\title{
Mediating Effects of Online-Based Leisure Between Parenting Attitudes and Children's Smartphone Dependency
}

\author{
Yoonju Cho \\ Instructor, Department of Child Studies, Chongshin Unversity, Seoul, Korea \\ 부모의 양육태도가 아동의 스마트폰 의존에 미치는 영향에서 \\ 온라인 여가의 매개효과 \\ 조윤주 \\ 총신대학교 강사
}

Objectives: This study investigated the impact of positive and negative parenting attitudes on smartphone dependency in children to examine the mediating effects of online-based leisure such as computer usage, game, and smartphone usage.

Methods: Data of 714 children scoring above the top 30\% of smartphone dependency among the children in 5th grade in elementary school were collected through the 2nd wave of the Korean Children and Youth Panel Survey (KCYPS 2018). Structural Equation Modeling (SEM) was applied to analyze the mediating effects with the Bootstrapping method by SPSS 21.0 and AMOS 20.0.

Results: In the model, online-based leisure significantly mediated the relationship between positive parenting attitudes such as warmth, autonomy support and structure provision, and smartphone dependency showing complete mediation. Also, negative parenting attitudes such as rejection, coercion, and chaos directly negatively affected smartphone dependency, not showing a mediating effect. Results indicate that increased positive parenting attitudes lead to reduced smartphone dependency through decreasing online-based leisure, while negative parenting attitudes lead to increase dependence on the smartphone.

Conclusion: While positive parenting attitudes do not directly affect smartphone dependency, they lead to a decrease in online-based leisure. Consequently, as online-based leisure lessens, smartphone dependency subsequently may also be diminished. In addition, although negative parenting attitudes have no mediating effect, they directly influence the growing smartphone dependency. Results confirm that positive parenting mediate the effects of online-based activities in relation to smartphone dependency when parents provide the most structure, autonomy support, and warmth to their children. Practical implications are discussed, and relevant interventions offered for children and parents.

Keywords: positive parenting attitudes, negative parenting attitudes, online-based leisure, smartphone dependency, mediating effect

Corresponding Author: Yoonju Cho, Instructor, Department of Child Studies, Chongshin University, 117, Dongjak-daero, Dongjak-gu, Seoul, Korea

E-mail: yjcho4@korea.ac.kr (c) The Korean Association of Child Studies

This is an Open Access article distributed under the terms of the Creative Commons Attribution Non-Commercial License (http:// creativecommons.org/licenses/by-nc/4.0) which permits unrestricted noncommercial use, distribution, and reproduction in any medium, provided the original work is properly cited. 


\section{Introduction}

\section{연구의 필요성 및 목적}

인터넷 기반의 인프라가 교육과 문화 등 삶의 전 영역에 걸 쳐 확장되고 온라인 매체와 밀착된 일상이 보편화되면서 스 마트폰 과의존에 속하는 아동의 비율이 증가하고 있다. 우리 나라의 스마트폰 사용률은 $\mathrm{OECD}$ 국가들 중 최고 수준으로 학령기 아동이 속한 십대의 사용률은 $97.6 \%$ 에 이른다(Korea Information Society Development Institute [KISDI], 2019). 과 학기술정보통신부에서 실시한 스마트폰 과의존 실태조사 (2020)에 의하면 2020년 현재 우리나라 십대의 $35.8 \%$ 가 스마 트폰 의존에 해당하고, 초등학교군에 속하는 아동의 $30.5 \%$ 가 스마트폰 과의존 위험군인 것으로 나타난다. 스마트폰 의존은 스마트폰이 없으면 우울하고 초조하여 일상생활에 집중하기 어렵고 다른 일에 방해가 될 만큼 스마트폰에 집착하는 심리 적 의존을 나타낸다(Han \& Huh, 2004). 이러한 의존은 학령기 아동의 신체적, 인지적 그리고 사회정서적 발달에 심각한 해 로움을 끼치며(Beland \& Murphy, 2014; Radesky, Schumacher, $\&$ Zuckerman, 2015), 부정적인 발달적 영향이 지속적인 영향 을 미칠 수 있어 적극적인 예방과 개입이 필요하다.

스마트폰 같은 미디어 의존은 주변 환경체계와 상호 의존 적으로 발달되는 특성이 있어(Ball-Rokeach \& DeFleur, 1976) 아동의 스마트폰 의존은 가장 밀접한 환경체계인 부모 요인 과의 관계 속에서 살펴볼 필요가 있다. 부모가 자녀와 상호작 용하고 개입하며 반응하는 양육의 질적이고 정서적인 태도는 아동의 스마트폰 의존을 저지하거나 강화시키는 데 중요하게 작용하는 가족 내 분위기 및 환경을 조성하는 주요 요인이 된 다(Buabbas, Hasan, \& Shehab, 2021). 또한 부모가 어떠한 태도 와 방식으로 양육하는 지에 따라 아동의 스마트폰 사용에 대 한 개입과 효과에 영향을 미치게 되므로(Ching \& Tak, 2017), 양육태도는 아동기 자녀의 스마트폰 의존에 중요한 영향 요소 로 볼 수 있다(Ching \& Tak, 2017; Vandewater, Park, Huang, \& Wartella, 2005). 부모의 양육 태도는 크게 부정적인 양육과 긍 정적인 양육으로 구분할 수 있는데 부정적인 양육은 강제적, 거부적, 그리고 비일관적인 방식으로 이루어지는 반면, 긍정 적인 양육은 애정적이고 자율성을 지지하며 문제해결에 대한 구조를 제공하는 방식으로 이루어진다(T. Kim \& Lee, 2017). 부정적인 양육태도로 강제적이고 거부적인 양육은 아동의 스 트레스 및 우울을 증가시켜 스마트폰과 같은 미디어 기기에 몰입을 이끈다(Kwak, Kim, \& Yoon, 2017). 또한 양육의 규칙
에 일관성이 없고 약속을 잘 지키지 않는 비일관적인 양육이 이루어질수록 자녀의 매체 의존은 증가하였고 스마트폰에 대 한 과다한 몰입이 나타났다(Noh \& Kim, 2016). 거부적이거나 무관심적인 양육이 이루어지는 경우에도 자녀의 스마트폰 이 용이 과도해졌고 중독이 증가하였다(Choi \& Kim, 2016). 반면 에, 부모가 애정을 바탕으로 따스하게 양육할수록 지지적이고 긍정적인 부모자녀 관계가 형성되어 자녀의 매체 의존에 보호 적인 역할을 하는 것으로 나타났다(Bae, 2015). 부모가 자녀의 스마트폰 사용에 관심을 갖고 모니터링을 하며 자율성을 존 중할수록 아동의 스마트폰 의존이 적었고(B. M. Kim, 2015; Moon \& Choi, 2015), 수용적이고 긍정적인 양육이 이루어질 수록 자녀의 스마트폰 중독이 낮게 나타났다(O. -H. Kweon \& Moo, 2018). 이러한 점들은 부모의 양육이 아동의 스마트폰 의존에 주요한 영향요인이 되며 양육태도에 따라 각기 다른 영향의 특성이 나타난다는 점을 제시해 준다.

한편, 인터넷을 기반으로 하는 온라인 활동의 영역이 교육, 오락, 사회 문화 등 다양한 영역으로 확장되면서 온라인을 통 한 여가활동이 증대되고 온라인 여가의 비중이 커지고 있다. 특히, 학령기 아동은 전체 여가에서 온라인 매체를 사용하는 여가의 비중이 가장 높았고, 초등학교군의 온라인 여가는 다 른 연령대에 비해 상당히 높게 나타났다(Ministry of Science and ICT [MSIT], 2020). 여가는 심신을 회복하거나 재미를 위해서 또는 자기발전을 위해서 여분의 시간에 자신의 의지대로 전 념하는 복합적인 활동의 총체를 말한다(Untaru, Albu \& Luca, 2014). 이러한 정의에 비추어 보면 온라인 여가는 인터넷을 기 반으로 온라인 매체를 이용하여 개인의 바램과 성향에 따라 여 분의 시간을 보내는 것이라 할 수 있다. 즉, 학습이나 정보 탐색 을 위한 목적이 아닌 오락적인 목적을 추구하면서 스마트폰과 컴퓨터로 노는 시간을 보내거나 동영상을 시청하거나 $\mathrm{SNS}$ 를 통한 사회적 관계형성 및 게임 등에 전념하는 것으로 볼 수 있 다. 여가의 구성과 특성은 자아개념의 발달, 유능성, 주도성, 그 리고 사회적 관계에 직접적으로 기여하게 되므로(Caldwell \& Witt, 2011), 학령기 아동이 여가를 보내는 방식은 건강한 심신 의 발달에 중요한 의미를 지닌다. 또한, 아동이 여가를 통해 놀 이와 활동에 전념하는 경험은 개인이 속한 사회와 문화에서 주 어진 역할과 상황을 재해석하게 함으로써 사회적 규칙에 대한 기대를 숙지하고 타인과 협력하며 사회적으로 적절한 행동양 상을 배우게 한다(Henderson, 2010). 이처럼 여가는 아동으로 하여금 건강한 사회정서적 발달의 기틀을 형성함과 동시에 사 회적 유능감을 획득하게 하고, 이렇게 획득된 유능감이 다시금 아동의 일상적인 행동양상으로 전환된다는 점에서 중요한 의 
미를 지닌다. 하지만, 현대사회에서 아동의 여가는 지속적으로 감소하고 있고, 특히 실외에서 환경과 접촉하며 능동적인 활 동을 하는 여가는 매우 큰 폭으로 감소해 왔다(Untaru, Albu \& Luca, 2014). 이에 비해 온라인 여가는 급속도로 증가하고 있는 데, 한국정보화진흥원 (2017)에 따르면 학령기 아동은 여가로 컴퓨터로 동영상을 시청하거나 게임 등을 하면서 많은 시간을 보내는 것으로 나타난다. 학령기 아동의 온라인 여가는 전체 여가에서 $45.3 \%$ 의 비중을 차지하였는데, 이는 여타 다른 활동 에 비해 월등히 높은 수치이다. 더욱이, 이들이 희망하고 선호 하는 여가활동 또한 스마트폰 이용이 $34.6 \%$ 를 차지하고 있어 문화예술 활동이나 스포츠와 같은 직접적인 경험보다 온라인 여가에 대한 선호가 높다는 것을 알 수 있다.

그런데, 아동의 온라인 여가에서 부모가 나타내는 양육의 태도는 중요한 영향을 미치게 된다(Lee, Kim, \& Yu, 2020). 왜 냐하면, 아동의 온라인 매체 사용과 온라인 활동 전반에 대 한 부모의 중재가 양육의 태도 및 방식에 의해 이끌어지기 때 문이다(Eastin, Greenberg, \& Hofschire, 2006). 더욱이 양육의 양상이 자녀의 인터넷 중독 같은 과다한 온라인 사용의 위험 을 초래하는 데 영향을 미칠 수 있는 만큼(Rosen, Cheever, \& Carrier, 2008) 아동의 온라인 여가는 양육태도와의 관계 속에 서 이해할 필요가 있다. 가령, 양육태도가 애정이 부족하고 무 관심하며 거부적인 경우에 아동의 온라인 사용은 증가하는 것 으로 나타났다(Duerager \& Livingstone, 2012). 또한, 부모의 양 육이 일관성이 없고 아동의 온라인 사용에 규칙이 없는 경우 에 자녀의 컴퓨터 사용이 과다해졌고, 게임 시간이 늘어났으 며 인터넷과 게임중독에 영향을 미쳤다(Ching \& Tak, 2017). 반면에, 부모가 아동에게 문제상황에 대한 설명과 대안을 제 시하고 관심을 기울이는 긍정적인 태도로 양육을 하는 경우는 온라인 매체에 대한 아동의 과도한 이용이 줄어들었고, 컴퓨 터 게임에 몰입하는 정도가 낮은 것으로 나타났다(Livingstone $\&$ Heper, 2008).

아동의 온라인 매체 사용과 증가에 대해서 일부 부모는 과 학기술적 조작 능력을 향상시킬 것이라는 긍정적인 평가를 하 기도 한다(Couse \& Chen, 2010). 하지만, 컴퓨터나 스마트폰 이 영유아도 쉽게 조작할 수 있는 만큼, 기대와 달리 과학기술 적인 조작 능력이 의미 있게 발달하는 효과를 나타내지 않았 다(Goldstein, 2012). 오히려, 오락 추구적인 온라인 여가가 증 가할수록 아동이 사회적 환경체계와 상호작용하고 정서적 교 류를 할 수 있는 다양한 경험의 기회가 줄어들기 쉽고, 신체 적, 사회정서적 발달에 역기능이 초래되기 쉽다(Lin, \& Chiang, 2017). 더욱이 여가를 통해 게임이나 오락, 그리고 동영상에 맹
목적이고 반복적으로 노출될수록 아동이 환경과 접촉하며 확 장할 수 있는 인지적, 정서적 상호작용의 기회 또한 제한될 수 있다(Carbonell, Oberst, \& Beranuy, 2013; Lin, \& Chiang, 2017). 실제로, 스크린 화면을 통해 일방향적이고 수동적인 여가가 이 루어지는 경우에 부정적인 심리적 증상이 높게 나타났고, 이와 달리 능동적이고 활동적인 여가에 참여할수록 정신 건강의 수 준이 높은 것으로 나타났다(Joudrey \& Wallace, 2009).

그럼에도 불구하고, 학령기 아동의 온라인 여가는 증가의 추세에 있으며((MSIT, 2020), 이러한 온라인 여가의 증가는 스 마트폰 의존을 부추기는 요인이 될 수 있다. 온라인 매체를 통 한 여가의 비중이 커지면서 스마트폰은 가장 편리하게 접촉 할 수 있는 매체로 각광받고 있는데, 특히 학령기 아동에게 스 마트폰 이용은 가장 선호되는 온라인 여가로 나타난다(MSIT, 2020). 이처럼 온라인 여가가 아동으로 하여금 스마트폰 이용 을 여가의 영역으로 확장시키고 있는 가운데 스마트폰에 대한 이용의 증가는 심리적인 몰입과 내성을 강화시켜 의존을 증가 시키게 된다(Lin, \& Chiang, 2017). 또한, 온라인 여가는 스크 린 매체에 시각화되어 있는 특징이 있어 온라인 여가의 증가 가 스크린에 대한 일방향적이고 맹목적인 몰입과 접촉을 증가 시킬 수 있다. 스크린 대면적 활동이 여가를 통해 반복될수록 스크린을 통한 시각적 자극에 고착되기 쉽고, 스크린 매체로 서 스마트폰에 대한 과잉 이용에 영향을 미칠 수 있다(Ching $\& \mathrm{Tak}, 2017)$. 실제로 아동의 스마트폰 사용에서 게임이나 동 영상 시청과 같은 스크린 몰두형 활동이 높은 비중을 차지하 고 있어(MSIT, 2021) 온라인 여가가 스크린 매체에 대한 몰입 을 촉진시킬 수 있음을 시사해 준다. Carbonell, Oberst, 그리 고 Beranuy (2013)에 의하면, 온라인을 통한 게임 역시 스마트 폰 의존을 예측하는 강력한 요인이 된다. 학령기 아동은 온라 인 여가로 게임에 대한 요구가 큰 것으로 나타나는데(Kawabe, Horiuchi, Ochi, Oka, \& Ueno, 2016), 컴퓨터로 오락을 하거나 게임을 많이 할수록 인터넷 중독이 높았던 것처럼, 게임으로 여가를 많이 보낼수록 스마트폰을 통한 게임의 증가와 더불어 의존성이 커지는 데 영향을 미쳤다(Cho, 2019).

더욱이, 스마트폰은 인터넷 기반의 인터페이스를 갖추고 다양한 응용 프로그램을 자유롭게 설치하고 작동할 수 있어 이용의 범위가 광범위한 만큼 여가와 여가 외에 명확한 구분 없이 사용되기가 쉽다. 여기에다 시간과 공간에 제약 없이 사 용 가능한 스마트폰의 기기적 특성까지 더해져 일정한 목적 없이 인터넷을 하며 시간을 보내거나 목적과 상관없이 인터넷 을 지속하는 일명 cyberloafing이 스마트폰을 통해 만연해지기 쉽다. 이러한 cyberloafing은 스마트폰 의존에 영향을 미치는 


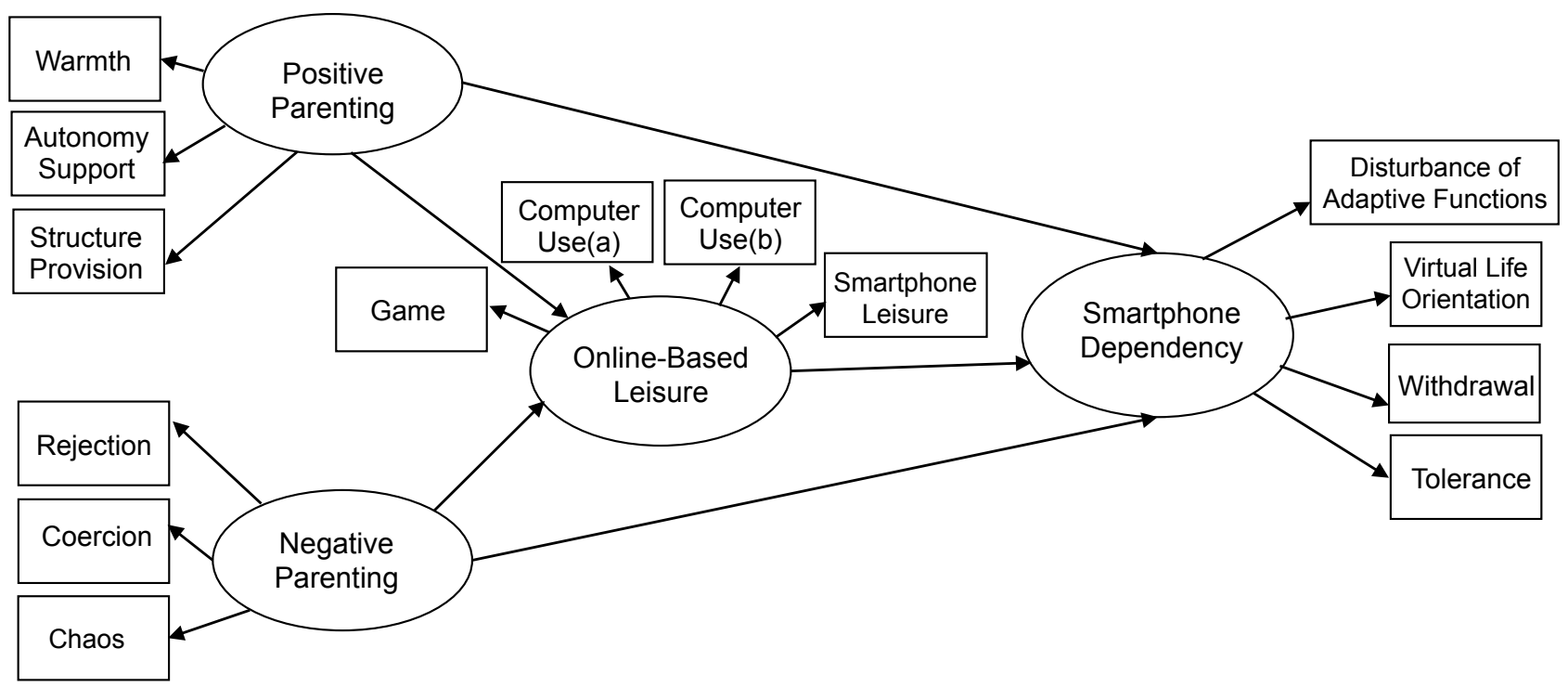

Figure 1. Mediation model of parenting attitudes on smartphone dependency

Table 1

Descriptive Characteristics of Participants

\begin{tabular}{llrr}
\hline & Variables & $N$ & $\%$ \\
\hline Children's gender & Male & 362 & 50.7 \\
& Female & 352 & 49.3 \\
\hline Children's age & 9 & 5 & .7 \\
& 10 & 705 & 98.7 \\
\hline Father's education & 11 & 4 & .6 \\
& High school or less & 212 & 29.9 \\
& College & 172 & 24.2 \\
& University & 239 & 33.7 \\
& Graduate school & 43 & 5.9 \\
& Missing & 48 & 6.1 \\
\hline Mother's education & High school or less & 225 & 31.7 \\
& College & 241 & 33.9 \\
& University & 189 & 26.6 \\
& Graduate school & 34 & 4.7 \\
& Missing & 25 & 3.1 \\
\hline Residential areas & Metropolitan city & 303 & 42.4 \\
& Medium-sized city & 298 & 41.7 \\
& Town & 113 & 15.9 \\
\hline
\end{tabular}

Note. $N=714$.

주요한 요소로 작용하는 만큼(Gökçearslan, Uluyol, \& Şahin,, 2018) 온라인 여가를 통해 특정한 목적 없이 스마트폰을 지속 적으로 사용하는 것에 각별한 주의가 필요하다.

지금까지 살펴본 바에 의하면, 학령기 아동의 스마트폰 의
존이 부모의 양육 태도와 온라인 매체를 통한 여가에 의해서 영향 받는다는 것을 알 수 있다. 부정적인 양육태도로서 강제 적이고 거부적이며 비일관적인 양육은 스마트폰에 대한 사용 과 의존을 증가시켰고(Ching \& Tak, 2017), 애정적이며 구조를 
제공하는 긍정적인 양육태도는 아동기 자녀의 스마트폰 의존 에 부적인 효과가 있었다(B. M. Kim, 2015). 양육의 태도는 아 동의 온라인 매체 사용의 정도와 컨텐츠에 주요한 영향 요인으 로 작용하였고(Lin, \& Chiang, 2017), 자녀의 온라인 이용 및 활 동과 양육태도 간에 밀접한 관련성이 보고되었다(Park, \& Cho, 2013). 또한, 아동이 컴퓨터와 게임 등 온라인을 통해 보내는 시간이 많아질수록 스마트폰에 대한 의존이 증가하는 것으로 나타났다(Lopez-Fernandez, et al., 2018). 이러한 점들을 근거로 하여 본 연구는 부모의 양육태도가 아동의 온라인 여가를 매 개로 하여 스마트폰 의존에 영향을 미친다는 점을 검증하려 한 다. 스마트폰 의존에 대한 선행연구들은 주로 청소년기를 대상 으로 하여 이루어져 왔지만 학령 후기 아동의 스마트폰 의존이 오히려 큰 폭으로 증가하는 것으로 나타난다(Jeong, 2019). 또 한, 학령기 아동의 여가에서 온라인 여가가 큰 비중을 차지하 면서 선호가 급격히 증가하는 것으로 나타나지만(MSIT, 2021) 스마트폰 의존에 대한 온라인 여가의 매개적 역할에 대한 변인 관계적인 연구는 아직까지 매우 드문 실정이다.

본 연구는 긍정적인 양육태도 및 부정적인 양육태도가 각 각 아동의 스마트폰 의존에 영향을 미치는 과정을 온라인 여 가를 매개변인으로 설정하여 검증하고자 한다. 이를 통해서 아동의 스마트폰 의존에 대한 양육태도의 특성과 온라인 여가 가 어떠한 관계 속에서 영향을 미치는 지를 파악하고 적절한 개입을 위한 이론적인 근거를 마련하고자 한다. 연구모형은 그림 1 에 제시하였고, 연구문제는 다음과 같다.

\section{연구문제 1}

아동의 스마트폰 의존에 대해 부모의 양육태도가 온라인 여 가를 매개로 영향을 미치는가?

1-1. 긍정적 양육태도가 온라인 여가를 매개로 스마트폰 의 존에 영향을 미치는가?

1-2. 부정적 양육태도가 온라인 여가를 매개로 스마트폰 의 존에 영향을 미치는가?

\section{Methods}

\section{연구대상}

한국아동청소년패널조사(Korean Children and Youth Panel
Survey [KCYPS])에서 2018년부터 구축한 2차년도(2019년)의 초등학교 5학년 자료 중에서 스마트폰을 사용한다고 답한 응 답자를 대상으로 하였다. 자료분석에는 스마트폰을 사용한다 고 답한 총 2,336 명 중 스마트폰 의존의 점수가 상위 $30 \%$ 에 해 당하는 714 명의 자료가 사용되었으며 남아는 362명(50.7\%), 여아는 352 명(49.3\%) 이었다. 본 자료에서 상위 $30 \%$ 의 스마 트폰 의존 점수는 4점 척도의 문항 평균이 2.2부터 3.6까지 해 당되어 의존이 거의 나타나지 않는 정도부터 높은 수준까지 포괄하는 범위로써 의존성향의 증감을 살펴보는 데 적합하다. 또한, 학령후기가 스마트폰 사용 및 온라인 여가의 비중이 높 아진다는 점(Jeong, 2019; MSIT, 2021)을 고려함과 동시에 교 급 전이기에 스트레스가 증폭한다는 점에서(Roeser, Eccles, \& Sameroff, 2000) 보다 보편적인 성향이 반영될 수 있는 5학년을 대상으로 하였다. 연구 대상자들의 인구학적 특성은 Table 1 에 제시하였다.

\section{연구도구}

\section{스마트폰 의존}

D. I. Kim 외 (2012)가 개발한 스마트폰 중독 자가진단 척도 가 사용되었다. 하위 영역은 일상생활장애가 5 문항, 가상세 계지향성이 2 문항, 금단이 4 문항, 내성이 4 문항으로 구성되 어 총 15 문항으로 이루어져 있다. 문항의 내용은 일상생활장 애 요인은 "수시로 스마트폰을 사용하다가 지적을 받은 적이 있다.", 가상세계지향성 요인은 "가족이나 친구들과 함께 있 는 것보다 스마트폰을 사용하고 있는 것이 더 즐겁다.”, 금단 요인은 "스마트폰을 사용할 수 없게 된다면 견디기 힘들 것이 다.”, “스마트폰이 없으면 안절부절 못하고 초조해진다.”, 내성 요인은 "스마트폰 사용에 많은 시간을 보내는 것이 습관화되 었다” 등으로 이루어졌다. 각 문항은 전혀 그렇지 않다(1점)부 터 매우 그렇다(4점)의 Likert식 4점 척도로 구성되어 있고, 경 우에 따라 역 채점 하였으며 점수가 높을수록 스마트폰 의존 이 높은 것을 의미한다. 문항 간의 신뢰도 계수인 Cronbach의 $\alpha$ 는 .80으로 일상생활장애가 .69, 가상세계지향성이 .66, 금 단이 .74, 내성이 .78 로 나타났다.

\section{긍정적 부모양육}

T. Kim 과 Lee (2017)의한국판 청소년용 동기모형 부모양육태 도척도(Parents as Social Context Questionnaire for Adolescents 
[PSCQ_KA])가 사용되었다. 긍정적 양육태도의 하위요인은 따스함, 자율성 지지, 구조제공으로 구성되어 있으며 각 요인 은 4문항씩 총 12 문항으로 이루어져 있다. 따스함 요인은, "부 모님은 나를 사랑하다는 것을 표현하신다.”, 자율성지지 요인 은 "부모님은 내가 중요하게 생각하는 일을 하게 해 주신다.", "부모님은 나의 생각을 이해하려고 노력 하신다.", 구조제공 요인은 "내게 문제가 있을 때 어떻게 해결해야할지 도움을 주 신다.", “부모님은 내게 규칙을 말씀하실 때 왜 지켜야하는 지 이유도 설명해주신다.”등으로 이루어져 있다. 각 문항은 전혀 그렇지 않다(1점)부터 매우 그렇다(4점)의 Likert식 4점 척도로 구성되어 있으며 점수가 높을수록 각 요인의 특성이 더 높은 것을 나타낸다. 문항 간의 신뢰도 계수인 Cronbach의 $\alpha$ 는 따 스함이 .87 , 자율성 지지가 .83 구조제공이 .77 로 나타났다.

\section{부정적 부모양육}

T. Kim 과 Lee (2017)의한국판 청소년용 동기모형 부모양육태 도척도[PSCQ_KA]중에서 부정적 양육 영역이 사용되었다. 하 위요인은 거부, 강요, 비일관성으로 구성되어 있으며, 각 요인 은 4문항씩 총 12 문항으로 이루어져 있다. 거부 요인은 "부모 님은 내가 방해가 된다고 생각하신다.”, 강요는 “부모님은 나 에게 이래라저래라 하신다.”, 비일관성은 “부모님이 약속을 해도, 지키실지는 알 수 없다.", "부모님은 나에 대한 규칙을 자주 바꾸신다.” 등의 문항으로 이루어져 있다. 각 문항은 전 혀 그렇지 않다(1점)부터 매우 그렇다(4점)의 Likert식 4점 척 도로 이루어져 있으며 점수가 높을수록 각 요인의 특성이 더 높은 것을 나타낸다. 문항 간 신뢰도 계수인 Cronbach의 $\alpha$ 는 거부가.76, 강요가 .71 비일관성이 .72로 나타났다.

\section{온라인 여가}

온라인 여가로는 컴퓨터를 가지고 노는 시간, 게임, 스마트폰 여가가 측정되었다. 컴퓨터로 노는 시간은 평일과 주말로 분 리하여 컴퓨터로 여가를 보내는 시간을 측정하였고, 전혀 안 함(1점)부터 4시간 이상-(7점)으로 각 30 분 단위마다 점수가 증 가되어 점수가 높을수록 컴퓨터로 노는 시간이 많은 것을 나 타낸다. 게임은 여가를 위해 스마트폰으로 게임을 하는 정도 를 반영하였고 전혀 하지 않는다(1점)부터 자주 사용한다(4 점)의 Likert식 4점 척도로 이루어져 있어 점수가 높을수록 게 임을 하는 정도가 많은 것을 나타낸다. 스마트폰 여가로는 오 락적인 목적 추구를 위해서 웹툰 및 웹북을 보는 것, 동영상의
시청, 그리고 SNS 활동의 정도가 반영 되었다. 전혀 하지 않는 다(1점)부터 자주 사용한다(4점)의 Likert식 4점 척도로 이루어 져 있으며, 점수의 합이 높을수록 스마트폰을 통한 여가가 많 이 이루어지는 것을 나타낸다.

\section{자료 분석}

수집된 자료는 SPSS 21.0 (IBM Co., Armonk, NY)과 AMOS 20.0 (IBM Co., Armonk, NY)로 분석하였다. 첫째, 변인들의 일 반적인 경향을 알아보기 위해서 기술 통계치를 분석하였다. 둘째, 연구모형인 매개모형의 적합성을 평가하기 위하여 적 합도 지수로 모형을 평가하였다. 모형의 적합도 평가는 경험 적인 근거와 간명성을 고려하였고(Browne \& Cudeck, 1993) 상대적 적합도 지수(Relative fit index)와 절대적 적합도 지수 (Absolute fit index)를 적용하였다. 셋째, 연구목표를 달성하기 위하여 설정한 연구모형인 매개모형을 통해서 변인들 간의 간 접효과와 직접효과를 분석하였다. 매개효과의 분석은 부트스 트랩방식을 적용하였고 표준화된 계수 값을 구하였다(Bollen $\&$ Stine, 1992).

\section{Results}

\section{변인들의 일반적 경향}

변인들의 일반적인 경향을 파악하기 위해서 기술통계치를 Table 2에 제시하였고, 모든 측정변인들이 왜도 및 첨도 값에 서 정규성 분포의 가정을 총족시키는 것으로 나타났다.

변인들 간의 상관관계는 Table 3에 제시하였다. 스마트폰 의 존은 애정적인 양육과 부적 상관이 나타났고 $(r=-.115, p<.01)$, 비일관적 양육과 정적 상관 $(r=.116, p<.01)$ 이 나타났다. 또한, 컴퓨터 여가 및 게임, 그리고 스마트폰 여가와는 각각 정적 상관 이 나타났다 $(r=.098, p<.01 ; r=.077, p<.01 ; r=1.25, p<.01)$.

\section{연구모형의 적합성}

본 연구에서 제시한 매개모형은 Table 4와 같이 적절한 수준 의 적합도가 있는 것으로 나타났다. 적합도 지수들에 대한 평 가는 TLI와 CFI의 경우에 .09 이상인 경우가 좋은 적합도로 평 가되고, RMSEA의 경우는 .07 미만이 양호한 적합도(resonable fit)로 평가된다(Browne \& Cudeck, 1993). 
Table 2

Descriptive Statistics

\begin{tabular}{|c|c|c|c|c|c|c|}
\hline \multicolumn{2}{|c|}{ Variables } & $M$ & $S D$ & Range & Skewness & Kurtosis \\
\hline \multicolumn{2}{|c|}{ Smartphone dependency } & 38.41 & 3.82 & $15-60$ & 1.16 & 1.49 \\
\hline \multirow[t]{3}{*}{ Positive parenting } & Warmth & 13.02 & 2.25 & $4-16$ & -.36 & .05 \\
\hline & Structure & 11.99 & 2.04 & $4-16$ & -.51 & 1.67 \\
\hline & Autonomy Support & 12.51 & 2.17 & $4-16$ & -.27 & .71 \\
\hline \multirow[t]{3}{*}{ Negative parenting } & Coercion & 9.73 & 2.28 & $4-16$ & .05 & .13 \\
\hline & Rejection & 8.14 & 2.54 & $4-16$ & .34 & -.30 \\
\hline & Chaos & 9.15 & 2.26 & $4-16$ & .17 & .15 \\
\hline \multirow[t]{4}{*}{ Online-based leisure } & Computer use(a) & 2.33 & 1.51 & $1-7$ & .78 & -.50 \\
\hline & Computer use(b) & 2.52 & 1.73 & $1-7$ & .62 & -.79 \\
\hline & Game & 3.33 & .83 & $1-4$ & -1.15 & .63 \\
\hline & Smartphone use & 9.43 & 2.40 & $2-14$ & -.07 & .09 \\
\hline
\end{tabular}

Note. $N=714$.

Table 3

Correlations Among Variables

\begin{tabular}{|c|c|c|c|c|c|c|c|c|c|c|c|c|}
\hline \multicolumn{3}{|c|}{ Variables } & 1 & 2 & 3 & 4 & 5 & 6 & 7 & 8 & 9 & 10 \\
\hline 1 & Smartphone depender & & - & & & & & & & & & \\
\hline 2 & Positive parenting & Warmth & $-.115^{* *}$ & - & & & & & & & & \\
\hline 3 & & Structure & -.056 & $.540^{* *}$ & - & & & & & & & \\
\hline 4 & & Autonomy support & -.072 & $.654^{* *}$ & $.540^{* *}$ & - & & & & & & \\
\hline 5 & Negative parenting & Coercion & .033 & $-.093^{*}$ & -.015 & $-.124^{* *}$ & - & & & & & \\
\hline 6 & & Rejection & .070 & $-.365^{* *}$ & $-.224^{* *}$ & $-.342^{* *}$ & $.470^{* *}$ & - & & & & \\
\hline 7 & & Chao & $.116^{* *}$ & $-.210^{* *}$ & -.058 & $-.211^{* *}$ & $.548^{* *}$ & $.531^{* *}$ & - & & & \\
\hline 8 & Online-based leisure & Computer use(a) & $.098^{* *}$ & $.613^{* *}$ & $.211^{* *}$ & $.651^{* *}$ & .027 & $.222^{* *}$ & $.109^{* *}$ & - & & \\
\hline 9 & & Computer use(b) & .051 & $-.161^{* *}$ & $-.124^{* *}$ & $-.173^{* *}$ & .025 & $.171^{* *}$ & $.091^{*}$ & $.822^{* *}$ & - & \\
\hline 10 & & Game & $.077^{*}$ & $.102^{* *}$ & .004 & .062 & $-.106^{* *}$ & $-.234^{* *}$ & $-.171^{* *}$ & -.066 & -.052 & - \\
\hline 11 & & Smartphone use & $.125^{* *}$ & -.056 & -.015 & -.025 & -.023 & .022 & .044 & $.199^{* *}$ & $.029^{* *}$ & .025 \\
\hline
\end{tabular}

Note. $N=714$.

${ }^{*} p<.05 .{ }^{* *} p<.01$.

Table 4

Goodness of Fit of the Mediation Model

\begin{tabular}{rccccc}
\hline Model & $\chi^{2}$ & $d f$ & TLI & CFI & RMSEA \\
\hline Mediation model & 304.47 & 71 & .892 & .916 & .068 \\
\hline
\end{tabular}

Note. $d f=$ degrees of freedom; TLI = Tucker-Lewis Index; CFI = comparative fit index; RMSEA = root mean square error of approximation.

\section{매개효과의 검증}

본 연구에서는 매개모형을 검증하기 위해서 간접효과 분석 에 효과적인 부트스트랩 방식을 적용하였고 각 경로의 계수 는 Table 5에 제시하였다. 부트스트랩 방식(bootstrapping)은 간 접효과 분석에서 표본의 크기에 영향 받지 않으면서 정상성이
위배된 경우에도 편향되지 않게 분석할 수 있는 강점이 있다 (Bollen \& Stine, 1992). 부트스트랩 방식을 적용한 매개효과의 검증은 $95 \%$ 신뢰수준에서 신뢰구간의 값이 0 을 포함하지 않으 면 영가설이 기각된다. Table 5가 제시하는 바와 같이 부모의 긍 정적 양육이 아동의 스마트폰 의존에 대해 나타내는 간접효과 는 신뢰구간에서 0이 포함되지 않아(-.052 -.013), 유의한 매개 
Table 5

Estimates from the Mediation Model

95\% CI of Indirect

Effect

\begin{tabular}{|c|c|c|c|c|c|c|}
\hline Mediation Model & $a$ & $\mathrm{~b}$ & $\mathrm{ab}$ & $c^{\prime}$ & Lower & Upper \\
\hline Positive parenting $\rightarrow$ Online-based leisure $\rightarrow$ Smartphone dependency & $-.194^{* * *}$ & $.159^{* * *}$ & $-.038^{* * *}$ & -.053 & -.052 & -.013 \\
\hline Negative parenting $\rightarrow$ Online-based leisure $\rightarrow$ Smartphone dependency & $.074^{* *}$ & $.159^{* * *}$ & .01 & $.174^{* * *}$ & -.001 & .025 \\
\hline
\end{tabular}

Note. Standardized paths are reported, $\mathrm{a}=\mathrm{X} \rightarrow \mathrm{M} ; \mathrm{b}=\mathrm{M} \rightarrow \mathrm{Y} ; \mathrm{c}^{\prime}=\mathrm{X} \rightarrow \mathrm{Y} ; \mathrm{CI}=$ Confidence Intervals.

${ }^{* *} p<.01 .{ }^{* * *} p<.001$.

Table 6

SMC of the Mediation Model

\begin{tabular}{lcccc}
\hline \multicolumn{1}{c}{ Mediation model } & Direct effect & Indirect effect & Total effect & SMC \\
\hline Positive parenting & -.053 & $-.031^{* *}$ & $-.084^{* * *}$ & .228 \\
Negative parenting & $.174^{* * *}$ & .012 & $.186^{* * *}$ & \\
\hline
\end{tabular}

${ }^{* *} p<.01 .{ }^{* * *} p<.001$.

효과가 나타났다( $\mathrm{ab}=-.03, p=.004)$. 또한, 매개변인을 통제한 상태에서 부모의 긍정적 양육이 스마트폰 의존에 대한 직접효 과는 유의하지 않아 $\left(c^{\prime}=-.053, p=.225\right)$ 완전 매개효과가 검증 되었다. 부모의 부정적 양육은 스마트폰 의존에 대한 간접효과 가 유의하지 않은 가운데(-.001 .025), $(\mathrm{ab}=.01, p=.314)$, 직 접효과가 유의한 것으로 나타났다 $\left(c^{\prime}=.174, p<.001\right)$.

즉, 긍정적인 양육태도는 아동의 온라인 여가가 감소하는 데 영향을 미쳤고, 이는 다시 스마트폰 의존에 부적인 영향을 미치면서 유의한 매개효과가 나타났다. 부모의 부정적 양육은 매개효과가 유의하지 않았지만 스마트폰 의존에 대한 직접적 인 정적 영향이 나타났다.

연구모형인 매개모형의 간접효과, 직접효과 및 총효과와 더 불어 다중상관치(Squared Multiple Correlations [SMC])는 Table 6에 제시하였다. 아동의스마트폰 의존에 대한 부모의 양육 및 온라인 여가의 설명력은 약 $22.8 \%$ 로 나타났다. 스마트폰 의존 에 대한 긍정적 양육의 간접효과는 -.053, 총효과는 -.083이었 고, 부정적 양육의 직접효과는 .174 , 총효과는 . 185 로 나타났다. 이러한 결과는 긍정적인 양육이 이루어질수록 아동의 온라인 여가가 줄어들면서 스마트폰 의존이 경감될 수 있다는 점을 말 해 주며, 부정적인 부모의 양육태도가 증가할수록 스마트폰 의 존이 증가하는 데 영향을 미친다는 점을 나타내 준다.

\section{Discussion}

본 연구는 아동의 스마트폰 의존에 대한 부모의 긍정적 양육
태도 및 부정적 양육 태도의 영향을 온라인 여가가 매개하는 지를 검증하였다. 연구결과, 긍정적인 양육태도는 온라인 여 가를 매개로 하여 아동의 스마트폰 의존에 간접효과를 나타내 었다. 즉, 긍정적인 태도로 부모의 양육이 이루어질수록 아동 이 온라인으로 여가를 보내는 정도가 줄어들었고, 이는 다시 스마트폰 의존이 경감되는 데 영향을 미쳤다. 또한, 부정적인 양육태도는 스마트폰 의존이 증가하는 데 직접적인 영향을 미 치는 것으로 나타났다. 결과에 대한 논의는 다음과 같다.

첫째, 긍정적인 양육태도는 아동의 스마트폰 의존에 대해 간접효과가 유의한 것으로 나타났다. 먼저, 긍정적인 태도의 양육이 증가하는 것은 아동의 온라인 여가가 감소하는 데 영 향을 미쳤다. 즉, 스마트폰 의존을 경감시키는 긍정적인 양육 의 효과는 아동의 온라인 여가를 감소시킴으로써 나타난다. 이러한 결과는 부모가 자녀와 따스한 관계를 형성하고 자율성 을 지지하며 문제상황을 예측하고 개입할수록 아동이 온라인 을 통해 여가를 보내는 정도가 감소된다는 것을 말해 주는 것 으로 부모의 양육이 아동의 게임 시간에 영향을 미친다는 결 과(S.-H. Kweon, \& Kweon, 2008)와 일맥상통하고, 양육태도에 따라 온라인 매체 사용에 영향을 미친다는 결과(Ching \& Tak, 2017; O. -H. Kweon \& Moo, 2018)를 지지한다.

긍정적인 양육태도가 아동의 온라인 여가를 감소시키는 데 영향을 미친다는 결과는 다음과 같은 점에서 의의가 있다. 학 령후기 아동은 자신이 속한 사회적 체계의 영향이 각기 다를 지라도 여가를 통해 어떠한 활동을 하며 시간을 보낼 지에 대 해서 자신의 욕구와 흥미를 반영한 자발적인 선택과 결정을 한다(Eccles, Barber, \& Stone, 2003). 이러한 자발적 선택이 온 
라인 여가를 통해 게임이나 동영상 시청 같은 의자 고정형 활 동에 치우치게 할수록 여가가 아동기 발달에 미치는 본질적인 효용과 가치에서 벗어나 오히려 발달적 역기능이 초래되기 쉽 다(Henderson, 2010). 그런데, 최근 학령후기 아동의 온라인 여 가는 전체 여가의 $45.3 \%$ 로(Ministry of Science and ICT [MSIT] 2021) 휴식, 취미활동, 스포츠 및 문화예술 경험과 같은 여타 의 여가활동을 모두 합친 것에 비견할 만큼 과도해지는 추세 이고, 본 연구 대상자들 역시 여가를 위한 게임과 스마트폰 사 용이 매우 높은 수준으로 나타나 온라인 집중적인 여가로 불 균형이 초래되고 있음을 제시해 준다. 이에 대해 본 연구 결 과는 학령후기 아동의 온라인 여가가 과잉 증대되는 것을 막 고 적정한 범위로 재구조화하기 위해서 부모의 일상적인 양 육태도로 긍정적인 양육이 중요한 지원이 될 수 있음을 제시 해 준다. 부모의 양육태도가 자녀의 온라인 매체 사용에 대한 환경 조성과 가족 분위기를 주도하는 만큼(Buabbas, Hasan, \& Shehab, 2021), 자녀와의 신뢰를 바탕으로 자율성을 지지하고 문제상황에 대한 상호작용 및 구조를 제공하는 긍정적인 양육 은 자녀의 온라인 여가에 대한 상호조정과 적정한 개입을 가 능하게 함으로써(Eastin, Greenberg, \& Hofschire, 2006) 온라인 여가가 감소하는 데 영향을 미친다고 볼 수 있다.

다음으로, 아동의 온라인 여가가 스마트폰 의존에 영향을 미치는 것으로 나타나, 긍정적인 양육으로 온라인 여가가 감 소할수록 스마트폰 의존이 경감되는 것으로 나타났다. 이러 한 결과는 온라인 매체의 사용이 스마트폰 의존에 영향을 미 친다는 결과(Lin, Chin, \& Jiang, 2015) 및 컴퓨터와 게임 이용 이 많을수록 스마트폰 중독 및 의존을 이끈다는 결과(Kawabe, Horiuchi, Ochi, Oka, \& Unen, 2016)와 그 맥을 같이 한다. 온라 인 여가의 감소가 스마트폰 의존을 경감시키는 측면에 대해서 는 다음과 같이 생각해 볼 수 있다. 우선, 온라인 여가에서 스 마트폰이 주류가 된다는 점을 주목할 수 있다. 학령 후기 아동 은 자연 친화적인 환경의 부재, 학업수행에 대한 과도한 요구 와 기대, 그리고 사교육과 공교육의 바쁜 일정 등으로 편리하 고 접촉이 용이한 동시에 즉각적인 만족을 얻을 수 있는 여가 를 선호한다. 컴퓨터와 스마트폰은 이러한 요구를 충족시키면 서 온라인 여가로서 선호와 사용이 증가하고 있다. 그런데, 본 연구에서 부가적인 분석을 실시한 결과, 스마트폰을 하며 노 는 시간이 컴퓨터로 노는 시간보다 많았고, 이러한 차이가 유 의한 것으로 나타났다( $\mathrm{t}=29.69, \mathrm{p}<.001)$. 이러한 점은 스마트 폰이 온라인 여가에서 주류 매체가 된다는 점을 반영하는 것 으로 온라인 여가의 감소가 스마트폰 사용을 줄어들게 함으로 써 의존이 경감될 수 있음을 시사해 준다.
또한, 온라인 여가가 스마트폰을 여가와 여가 외에서 연속 적으로 사용하게끔 한다는 점에 주목할 수 있다. 연속적인 스 마트폰의 사용은 여가이외에 다른 사용목적과 경계를 모호하 게 하면서 목적에 상관없이 스마트폰을 지속적으로 사용하게 끔 하는 무분별성을 증가시킨다. 여가를 통해 스마트폰 사용 이 연속적으로 이루어지는 것은 일상생활에서 스마트폰 사용 의 경계를 모호하게 하고 스마트폰과 일상을 분리시키지 못하 는 내성과 금단을 강화시킨다(Jiang \& Li, 2018). 따라서 온라 인 여가의 감소는 스마트폰 사용에서 연속성을 강화시키지 못 함으로써 여가외 사용에 대한 경계를 인식시키고 의존을 경감 시킬 수 있다.

Jiang 과 Li (2018)에 의하면, 여가의 지루함은 스마트폰 에 대한 의존을 이끌게 된다. 온라인 사용의 증가는 여가로 마땅히 할 일이 없는 지루함에서 이끌어 지며(Iso-Aloha \& Weissinger, 1990), 이러한 지루함은 스마트폰 과잉 이용 및 의 존을 촉진시키게 된다(Leung, 2008). 학령기 아동의 경우에 스마트폰은 지루함을 덜 수 있는 편리한 오락추구적 방편이 된다. 하지만, 여가가 아동의 발달에 미치는 사회정서적 중 요성을 고려하면 온라인 여가가 다양한 실제적 활동과 균형 을 이룰 수 있어야 하겠다. 이를 위해서 학령기 아동의 발달 을 고려한 다양한 여가 활동 프로그램들이 개발되어야 하겠 고, 방과 후 활동 및 지역사회 체계들을 통해서 접근이 용이 할 수 있도록 기회가 제공되어야 하겠다. 무엇보다도, 온라 인 여가의 편리성 이면에 역기능적 한계점을 보완할 수 있 는 대안이 모색되어야 하겠으며 관련 연구의 진행과 함께 구 체적인 지원 방안도 마련되어야 하겠다. 특히, 학령 후기 아 동은 호기심의 범위가 확대되고 자극 추구에 대한 욕구가 커 지는 만큼(Steinberg, Albert, Banich, Cauffman, Graham, \& Woolard,2008) 온라인 여가가 스마트폰을 통한 오락 추구를 넘어서 적정한 경계와 범위를 벗어나 중독이나 일탈로 이끌어 지지 않도록 주의가 요구된다.

둘째, 부정적인 부모의 양육은 스마트폰 의존에 대해 간접 효과가 유의하지 않은 가운데 직접효과가 유의한 것으로 나 타났다. 즉, 거부적이고 강요적이며 비일관적인 양육태도는 아동의 스마트폰 의존이 증가하는 데 직접적인 영향을 미치 게 된다. 이러한 결과는 부정적인 양육이 이루어질수록 자녀 의 매체 의존이 증가한다는 연구와 일맥상통하며(Kwak, Kim, $\&$ Yoon, 2017), 무관심적이고 비일관적인 양육이 과도한 온라 인 사용을 이끈다는 결과를 지지한다(Ihmeideh \& Shawareb, 2014). 부모의 강제적이고 규칙이 부재한 일관성 없는 양육태 도는 아동에게 불안 및 초조와 같은 부정적인 정서를 유발시 
키고, 밀접한 대상과의 신뢰를 깨뜨려 부정적인 관계를 형성하 게 하므로 아동은 상호작용에 대한 회피 심리와 스트레스 탈 피의 방편으로 스마트폰에 몰입하기 쉽다(Kwak, Kim, \& Yoon, 2017). 또한, 거부적이고 강압적인 양육태도는 아동으로 하여 금 부정적인 자기형성과 자율성을 약화시켜 스마트폰에 대한 의존성을 증가시킨다(Choi \& Kim, 2016). 온라인 사용이 급증 하는 아동의 일상적 환경에서 부정적인 양육태도가 스마트폰 의존에 미치는 부정적 효과를 인식하고, 스마트폰 의존이 증가 되지 않도록 양육태도를 반영한 부모교육 및 프로그램이 구체 화되고 다양한 체계를 통해 시행되어야 할 것이다. 한편, 부정 적인 양육태도에서 간접 효과가 나타나지 않았던 결과는 스마 트폰 의존에 대한 양육태도의 영향이 각기 다른 경로와 특성을 나타낸다는 점을 말해 준다. 즉, 긍정적인 양육태도는 아동의 온라인 여가가 과다해지지 않도록 제어하는 동력으로 작용하 여 스마트폰 의존을 경감시키는 것에 비해, 부정적인 양육태도 는 아동의 스마트폰 의존을 증가시키는 직접적인 요인이 된다. 따라서, 학령기 아동의 스마트폰 의존에 효과적인 부모의 개입 이 이루어지려면 긍정적인 양육을 통한 과잉 온라인 여가의 방 지와 더불어 부정적인 양육이 초래하는 직접적인 부정적 효과 또한 차단하고 예방하는 데 주안점을 두어야 할 것이다.

연구의 제한점과 기대효과는 다음과 같다. 본 연구는 비교 적 최근의 동향을 반영한 패널데이터를 활용하여 다수의 자료 를 분석에 포함시켜 부트스트랩 방식으로 연구모형의 매개효 과를 분석하였다. 하지만, 부모의 양육태도가 아동이 지각한 부모의 양육이라는 점에서 일방향적인 측면만이 반영되었고, 온라인 여가가 아동의 자기 보고식 평가로 이루어져 있다는 점 에서 다중 측정이 이루어지지 못한 한계가 있을 수 있다. 긍정 적인 양육태도의 완전매개 효과가 나타나 스마트폰 의존에 대 한 온라인 여가의 매개적 중요성이 시사되었지만, 완전매개 효 과에서 나타난 매개변인이 유일한 매개요인은 아니라는 점에 유의하여(Rucker, Preacher, Tormala, \& Petty, 2011) 다양한 관련 변인들에 대한 탐색이 시도될 필요가 있다. 향후 연구에서는 학령기 온라인 여가의 증가에 따른 변화를 반영하여 관련 변인 들 간의 중재와 조절효과에 대한 검증이 이루어지길 기대한다.

\section{Acknowledgements}

This study was supported by the Ministry of Education of the Republic of Korea and the National Research Foundation of Korea (NRF-2019S1A5B5A07112209).

\section{Conflict of Interest}

No potential conflict of interest relevant to this article was reported.

\section{References}

\section{In English}

Bae, S. M. (2015). The relationships between perceived parenting style, learning motivation, friendship satisfaction, and the addictive use of smartphones with elementary school students of South Korea: Using multivariate latent growth modeling, School Psychology International, 36(5), 513-531. doi: $10.1177 / 0143034315604017$

Ball-Rokeach, S. J., \& DeFleur, M. L. (1976). A dependency model of mass-media effects. Communication Research, 3(1), 3-21. doi:10.1177/009365027600300101

Beland, L., \& Murphy, R. J. (2014). Ill Communication: Mobile Phones \& Student Performance. London: London School of Economics and Political Science.

Bollen, K. A.. \& Stine, R. A. (1992). Bootstrapping goodness-of-fitmeasures in structural equation models. Sociological Methods and Research, 21(2), 205-229. doi:10.1177/0049124192021002004

Browne, M. W., \& Cudeck, R. (1993). Alternative ways of assessing model fit. In K. A. Bollen \& J. S. Long (Ed.), Testing structural equation models(pp.136-162). Newbury Park, CA: Sage. doi:10.1177/0049124192021002005

Buabbas A., Hasan, H., \& Shehab, A. A. (2021). Parents' attitudes toward school students' overuse of smartphones and its detrimental health impacts: Qualitative study. JMIR Pediatrics and Parenting, 4(2), 1-12. doi:10.2196/24196

Caldwell, L. L., \& Witt, P. A. (2011). Leisure, recreation, and play from a developmental context. Recreation as a Developmental Experience, 130, 13-27. doi:10.1002/yd.394

Carbonell, X., Oberst, U., \& Beranuy, M. (2013) 'The cell phone in the twenty-first century: A risk for addiction or a necessary tool?'. in Miller, P. A. (Ed..), Principles of addiction. Comprehensive Addictive Behaviors and Disorder(pp.901-909). San Diego: Elsevier Academic Press.

Ching, K. H., \& Tak, L. M. (2017). The structural model in parenting style, attachment style, self-regulation and selfesteem for smartphone addiction. Journal of Psychology o the Behavioral Science, 3(1), 85-103. doi:10.22492/ ijpbs.3.1.06

Couse, J., \& Chen, W. (2010). A tablet computer for young 
children? Exploring its viability for early childhood education. Journal of Research on Technology in Education, 43, 75-98. doi:10.1080/15391523.2010.10782562

Duerager, A. \& Livingstone, S. (2012). How can parents support children's internet safety? EU Kids Online, London, UK. Retrived from at: http://eprints.lse.ac.uk/42872/

Eastin, M. S., Greenberg, B. S., \& Hofschire, L. (2006). Parenting the internet. Journal of Communication, 56, 486-504. doi:10.1111/j.1460-2466.2006.00297.x

Eccles, J., Barber, B., Stone, M., \& Hunt, J. (2003). Extracurricular activities in adolescent development. Journal of Social Issues, 59, 865-889. doi:10.1046/j.0022-4537.2003.00095.x

Goldstein, J. (2012) Play in Children's Development, Health and Well-Being. Brussels. Toy Industries of Europe (TIE).

Henderson, K. (2010). Leisure studies in the 21St century: The sky is falling? Leisure Sciences: An Interdisciplinary Journal, 32(4), 391-400. doi:10.1080/01490400.2010.488614

Ihmeideh, F. M., \& Shawareb, A. A. (2014). The association between Internet parenting styles and children's use of the Internet at home. Journal of Research in Childhood Education, 28(4), 411-425. doi:10.1080/02568543.2014. 944723

Iso-Ahola, S. E., \& Weissinger, E. (1990). Perceptions of boredom in leisure: Conceptualization, reliability and validity of the leisure boredom scale. Journal of Leisure Research, 22(1), 1-17. doi:10.1080/00222216.1990.11969811

Jiang, Q., \& Li, Y. (2018). Factors affecting smartphone dependency among the young in China. Asian Journal of Communication, 28(5), 508-525, doi:10.1080/01292986.2 018.1431296

Joudrey, A. D., \& Wallace, J. E. (2009) Leisure as a coping resource: A test of the job demand-control-support model. Human Relations, 62, 195-217. doi:10.1177/0018726708100357

Kawabe, K., Horiuchi, F., Ochi, M., Oka, Y., \& Ueno, S. (2016). Internet addiction: Prevalence and relation with mental states in adolescents. Psychiatry Clinical Neuroscience, 70(9), 405-412. doi:10.1111/pcn.12402

Kwak, J. Y., Kim, J. Y., \& Yoon, Y. W., (2017). Effect of parental neglect on smartphone addiction in adolescents in South Korea, Child Abuse \& Neglect, 77, 75-84. doi:10.1016/ j.chiabu.2017.12.008

Leung, L. (2008). Linking psychological attributes to addiction and improper use of the mobile phone among adolescents in Hong Kong. Journal of Children and Media, 2(2), 93113. doi:10.1080/17482790802078565

Lin, T. T. C., \& Chiang, Y.-H. (2017). Investigating predictors of smartphone dependency symptoms and effects on academic performance, improper phone use and perceived sociability. International Journal of Mobile Communications, 15(6), 655-676. doi:10.1504/IJMC.2017.10005647.
Lin, T. T. C., Chiang, Y.-H. \& Jiang, Q. (2015). Sociable people beware? Investigating smartphone versus nonsmartphone dependency symptoms among young singaporeans Social Behavior and Personality: an international journal, 43(7), 1209-1216. doi:10.2224/sbp.2015.43.7.1209

Livingstone, S., \& Helsper, E. (2008). Parental mediation of children's Internet use. Journal of Broadcasting \& Electronic Media, 52(4), 581-599. doi:10.1080/08838150802437396

Lopez-Fernandez, O., Männikkö, N, Kääriäinen, M., Griffiths, M. D., \& Kuss1, D. J. (2018). Mobile gaming and problematic smartphone use: A comparative study between Belgium and Finland. Journal of Behavior Addiction. 7(1): 88-99. doi:10.1556/2006.6.2017.080

Radesky, J. S., Schumacher, J., \& Zuckerman, B. (2015). Mobile and interactive media use by young children: The good, the bad, and the unknown. Pediatrics, 135(1), 1-3. doi:10.1542/peds.2014-2251

Rosen, L. D., Cheever, N. A., \& Carrier, L. M. (2008). The association of parenting style and child age with parental limit setting and adolescent myspace behavior. Journal of Applied Developmental Psychology, 29, 459-471. doi:10.1016/ j.appdev.2008.07.005

Roeser, R. W., Eccles, J. S., \& Sameroff, A. J. (2000). School as a context of early adolescents' academic and social-emotional development: A summary of research findings. The Elementary School Journal, 100(5), 443-471. doi:10.1086/499650

Gökçearslan, Ş., Uluyol, Ç., \& Şahin, S.(2018). Smartphone addiction, cyberloafing, stress and social support among university students: A path analysis. Children and Youth Services Review, 91, 47-54. doi:10.1016/ j.childyouth.2018.05.036

Steinberg, L., Albert, D., Banich, M., Cauffman, E., Graham, S., \& Woolard, J. (2008). Age differences in sensation seeking and impulsivity as indexed by behavior and self report: Evidence for a dual systems model. Developmental Psychology, 44(6), 1764-1778. doi:10.1037/a0012955

Untaru, E. N., Albu, R. G., \& Luca, M. R. (2014). Parents and their involvement in children's leisure activities. Bulletin of the Transilvania University of Braşov Series VII: Social Sciences Law, 7(56) 63-72.

Vandewater, E. A., Park, S. E., Huang, X., \& Wartella, E. A. (2005). No -You can't watch that: Parental rules and young children's media use. The American Behavioral Scientist, 48(5), 608-623. doi:10.1177/0002764204271497

Valcke, M., Bonte, S., De Wever, B., \& Rots, I. (2010). Internet parenting styles and the impact on internet use of primary school children. Computers \& Education, 55(2), 454-464. doi:10.1016/j.compedu.2010.0 


\section{In Korean}

Cho, Y. (2019). Trajectory of smartphone dependency and associated factors in school-aged children. Korean Journal of Child Studies 40(6), 49-62. doi:10.5723/kjcs.2019.40.6.49

Choi, T.-S., \& Kim, J.-K. (2016). The effects of parental overintrusiveness on elementary school students' mobile phone dependency: mediating roles of social withdrawal and depression. Korean Journal of Youth Studies, 23(3). 393414.

Han, J. L., \& Hur, G. H. (2004). Construction and validation of mobile phone addiction scale. Korean Journal of Journalism \& Communication Studies, 48(6), 138-165.

Jeong, Y. (2019). Homo seumateuponikuseu, sedaebyeol jinhwa sokdo [호모 스마트포니쿠스, 세대별 진화 속도](Report No. 19-14). Retrieved from NKIS of website: www.nkis. re.kr:4445/main.do.

Kim, B. M. (2015). Effects of simulated autonomous control rearing attitude and parent-child communication on smartphone addiction tendency among children (Master's thesis). Retrieved from https//dcollection.jnu.ac.kr/public_resource $/ \mathrm{pdf}$

Kim, D. -I., Chung, Y. -J., Lee, J. -Y., Kim, M. -V., Lee, Y. -H., Kang, E. -B., Keum, C. -M., \& Nam, J. -E. (2012). Development of smartphone addiction proneness scale for adults: self-report. Korean Journal of Counseling, 13(2), 629644. doi:10.15703/kjc.13.2.201204.629

Kim, T., \& Lee, E. (2017). Validation of the korean version of parents as social context questionnaire for adolescents: PSCQ_KA. Korean Journal of Youth Studies, 24(3), 313333. doi: 10.21509/KJYS.2017.03.24.3.313

Kweon, O. -H., \& Moo, J. -W. (2018). The effect of positive parenting attitude on mobile phone dependency -A convergent approach to the mediating effects of ego-resiliency and gendermoderating effects. Journal of Convergence for Information Technology 8(4), 145-152. doi:10.22156/CS4SMB. 2018.8.4.145

Kweon, S. -H., \& Kweon S. -N. (2008). The effect of children's perception of parenting attitude and learned helplessness on computer game addiction, Journal of the Korea Society of Computer and Information, 13(4), 59-69.
Lee, G., Kim, S., \& Yu, H. (2020). Parental factors associated with smartphone overuse in preschoolers: A systematic review and meta-analysis. Journal of Korean Academy of Nursing. 50(3), 349-368. doi:10.4040/jkan.19186

Ministry of Science and ICT (2020). 2020 The survey on smartphone overdependence. Sejong: Ministry of Science and ICT

Moon D. -S., \& Choi, E. -S. (2015). The effect of parental rearing attitudes on smart phone addiction of adolescents: The mediating effect of self-esteem. Korean Journal of Youth Studies, 22(10), 213-236.

National Youth Policy Institute(2019). Korean Children and Youth Panel 2018 Survey 2nd survey of 5th grade [Data file and code book]. Retrieved from January 5, 2021, from https:// www.nypi.re.kr/archive/mps

Noh, C., \& Kim, S. (2016). The effects of parenting attitudes on adolescents'smartphone dependency: The mediating effects of adolescents'depression and aggression. Studies on Korean Youth, 27(4), 87-114. doi:10.14816/sky.2016.27. 4.87

Park, G. S., \& Cho, O. K. (2013). The effect of social support on high school-students' career preparation behavior: The role of career decision-making self-efficacy as a mediator. Theory and Practice of Education 23, 125-142.

\section{ORCID}

Yoonju Cho http://orcid.org/0000-0002-4346-6965

Received August 31, 2021

Revision received October 1, 2021

Accepted December 12, 2021 